\title{
JOINTLY SUBADDITIVE MAPPINGS INDUCED BY OPERATOR CONVEX FUNCTIONS
}

\author{
MAREK NIEZGODA
}

Abstract. In this paper, we study jointly subadditive mappings induced by operator convex functions and generalized inverses of positive linear maps. We formulate conditions under which the inequalities $T f T^{-}\left(\sum_{k=1}^{n} T_{k} A_{k}\right) \leqslant \sum_{k=1}^{n} T_{k} f\left(A_{k}\right)$ and $T f T^{-} \Phi(A) \leqslant \Phi(f(A))$ hold, where $f$ is an operator convex function, $A, A_{k} \in \mathbb{B}(H)$ with Hilbert space $H$, and $T, T_{k}$ and $\Phi$ are positive linear maps (not necessarily unital) on $\mathbb{B}(H)$, with a (reflexive) generalized inverse $T^{-}$of $T$. We also show that the transformation $T f T^{-}(B)$ is jointly subadditive in $(T, B)$ and antimonotone in $T(I)$.

Mathematics subject classification (2010): 39B62, 26D15, 52A40, 06F20.

Keywords and phrases: Operator convex function, positive linear map, operator Jensen inequality, Choi-Davis-Jensen's inequality, sub-/superadditive mapping, generalized inverse.

\section{REFERENCES}

[1] N. BEBIANO, R. LAMOS AND J. DA PROVIDENCIA, Inequalities for quantum relative entropy, Linear Algebra Appl., 401 (2005), 159-172.

[2] M. Burgos, A. C. Márquez-García And A. Morales-Campoy, Linear maps strongly preserving Moore-Penrose invertibility, Operators and Matrices, 6 (4) (2012), 819-831.

[3] I. CSISZÁR, Information-type measures of differences of probability distributions and indirect observations, Studia Sci. Math. Hung., 2 (1967), 299-318.

[4] I. CSISZÁR AND J. KÖRneR, Information Theory: Coding Theorems for Discrete Memory-less Systems, Academic Press, New York, 1981.

[5] M. D. CHOI, A Schwarz inequality for positive linear maps on $C^{*}$-algebras, Illinois J. Math., 18 (1974), 565-574.

[6] C. Davis, A Schwarz inequality for convex operator functions, Proc. Amer. Math. Soc., 8 (1957), $42-44$.

[7] S. S. DRAGOMIR, A refinement of Jensen's inequality with applications for $f$-divergence measures, Taiwanese J. Math., 14 (1) (2010), 153-164.

[8] E. G. EFFros, A matrix convexity approach to some celebrated quantum inequalities, Proc. Natl. Sci. USA, 106 (2009), 1006-1008.

[9] J. I. FUJII AND E. KAMEI, Relative operator entropy in noncommutative information theory, Math. Japon., 34 (1989), 341-348.

[10] F. HANSEN, J. PeČARIĆ AND I. PERIĆ, Jensen's operator inequality and its converses, Math. Scan., 100 (2007), 61-73.

[11] R. Harte And M. Mbekhta, On generalized inverses in $C^{*}$-algebras, Studia Math., 103 (1992), 71-77.

[12] R. A. Horn And C. R. Johnson, Topics in Matrix Analysis, Cambridge University Press, Cambridge, 1991.

[13] S. IVelić, A. MatKović And J. E. PeČARIĆ, On a Jensen-Mercer operator inequality, Banach J. Math. Anal., 5 (2011), no. 1, 19-28.

[14] R. Kaur, M. Singh, J. S. Aujla and M. S. Moslehian, a general double inequality related to operator means and positive linear maps, Linear Algebra Appl., 437 (2012), 1016-1024. 
[15] M. Khosravi, Corach-Porta-Recht inequality for closed range operators, Math. Inequal. Appl., 16 (2) (2013), 477-481.

[16] M. Khosravi, J. S. Aujla, S. S. Dragomir and M. S. Moslehian, Refinements of Choi-DavisJensen's inequality, Bull. Math. Anal. Appl., 3 (2011), 127-133.

[17] F. Kubo And T. Ando, Means of positive linear maps, Math. Ann., 246 (1980), 205-224.

[18] J. MićIĆ, Z. PAVIĆ AND J. PEČARIĆ, Jensen's inequality for operators without operator convexity, Linear Algebra Appl., 434 (2011), 1228-1237.

[19] J. Mićić, J. PeČARIĆ AND J. PERIĆ, Extension of the refined Jensen's operator inequality with condition on spectra, Ann. Funct. Anal., 3 (2012), no. 1, 67-85.

[20] J. MićIĆ, J. PEČARIĆ AND J. PERIĆ, Refined Jensen's operator inequality with condition on spectra, Operators and Matrices, 7 (2013), 293-308.

[21] B. Mond AND J. PeČARIĆ, Converses of Jensen inequality for several operators, Rev. Anal. Numer. Theor. Approx., 23 (1994), 179-183.

[22] M. S. Moslehian ANd M. Kian, Non-commutative $f$-divergence functional, Math. Nachr., 286 (2013), 1514-1529.

[23] M. NiEZGodA, On sub-and superadditive vector-valued maps with applications to group majorization, Linear Algebra Appl., 438 (11) (2013), 4249-4259.

[24] C. R. Rao And S. M. Mitra, Generalized inverse of a matrix and its applications, Proc. Sixth Berkeley Symp. on Math. Statist. and Prob., Vol. 1, Univ. of Calif. Press, 601-620, 1972.

[25] Y. Tian AND G. P. H. STYAn, On some matrix equalities for generalized inverses with applications, Linear Algebra Appl., 430 (2009), 2716-2733.

[26] Q. Xu And L. Sheng, Positive semi-definite matrices of adjointable operators on Hilbert $C^{*}$ modules, Linear Algebra Appl., 428 (2008), 992-1000.

[27] Q. XU AND X. ZHANG, The generalized inverses $A_{T, S}^{(1,2)}$ of the adjointable operators on the Hilbert $C^{*}$-modules, J. Korean Math. Soc., 47 (2) (2010), 363-372. 